\title{
Evaluation of Current Status of Newly Established Model Pharmacies in Bangladesh
}

\author{
Shadhan Kumar Mondal ${ }^{1}$, Sabiha Chowdhury ${ }^{1}$, Amlan Ganguly ${ }^{1}$ \\ and A.B.M. Faroque ${ }^{2}$
}

\author{
${ }^{1}$ Department of Clinical Pharmacy and Pharmacology, University of Dhaka, Dhaka-1000, Bangladesh \\ ${ }^{2}$ Department of Pharmaceutical Technology, University of Dhaka, Dhaka-1000, Bangladesh
}

(Received: November 08, 2018; Accepted: December 9, 2020; Published (web): January 02, 2021)

\begin{abstract}
Pharmaceutical sector of Bangladesh has developed profoundly after promulgation of the Drugs (Control) Ordinance, 1982. However, the health sector has not been equally developed because of lack of wellequipped drug management system and much needed patient counseling. The presence of adulterated, counterfeit and substandard drugs and the sale of drugs at high prices than the maximum retail price have also been the major problems here. The recent introduction of model pharmacies is supposed to be a hope for the people to get safe medicines at a reasonable cost. The aim of the present study was to find out the current scenario of model pharmacies in Bangladesh and to propose modern and alternative systems that could be applied in model pharmacies for better healthcare management and patient compliance. Thus, the current status of model pharmacies of Bangladesh has been evaluated using a survey-based analysis which utilized a pre-set questionnaire. The survey was conducted on 90 model pharmacies in seven districts of Bangladesh (Level 1 categorized by the Directorate General of Drug Administration, Government of the People's Republic of Bangladesh). The results revealed that the infrastructure of the model pharmacies should be improved further. Only $33 \%$ of the model pharmacies have sitting facilities and $51 \%$ of them have washroom facilities for the waiting patients. It was found that despite all the model pharmacies (100\%) should have at least 1 A-grade pharmacist in each of them, i.e. a pharmacy graduate registered with the Pharmacy Council of Bangladesh under the Pharmacy Ordinance 1976, but pharmacists were found to be present in only $26 \%$ of pharmacies during the visit. Amongst the pharmacists, $98 \%$ showed satisfaction with the decision of compulsory engagement of A-grade pharmacists in all the model pharmacies. Defying the obligatory provisions, only $38 \%$ model of pharmacies keep the required records of sold drugs. It was pleasing to observe that no physician's sample of medicines was sold in any model pharmacies. The medicines storage facilities in controlled temperature was found in all the model pharmacies. But the A-grade pharmacists were not available in the pharmacies during holidays. It is opined that modern and ICT based techniques can be applied to modify the model pharmacies for better patient care and patient management.
\end{abstract}

Key words: Model pharmacy, patient counseling, A-grade pharmacist, adverse drug reaction

\section{INTRODUCTION}

The Government of Bangladesh (GoB) is determined to provide effective health care service for the people of Bangladesh. Directorate General of Drug Administration (DGDA), which is the drug regulatory authority under the Ministry of Health and Family Welfare (MOHFW), has formulated a series of guidelines including easy access to safe and good quality drugs at affordable price and rational use of drugs to meet the objectives.

\section{Correspondence to: A B M Faroque}

E-mail: abmfaroque@yahoo.com

Dhaka Univ. J. Pharm. Sci. 20(1): 1-10, 2021 (June)

DOI: https://doi.org/10.3329/dujps.v20i1.50852
After the independence of Bangladesh, multinational companies had been dominating our pharmaceutical sector and we had to import more than $80 \%$ medicines to meet our annual demand. But a revolutionary change occurred after the proclamation of the Drug (Control) Ordinance, 1982. Now-a-days, we do meet $97 \%$ of our local demand of medicines and export medicines to 145 countries. ${ }^{1}$ There are also 269 allopathic pharmaceutical companies licensed by the DGDA. A good number of pharmaceutical companies of Bangladesh have got approval from renowned regulatory and certification authorities across the world. As a result, 
pharmaceutical sector of Bangladesh now becomes the second highest foreign currency earner in the country and thus it is widely considered as a "hi-tech" industry. ${ }^{2}$

Private pharmacies are "first point of call" for medical advice on common health problems. ${ }^{3}$ People prefer these drug stores to the government hospitals. A lot of poor people of the country are not capable to consult a physician. So, the private medicine retailers have turned to be one of the principal players in promoting access to medicines in the country like Bangladesh. According to DGDA the number of licensed drug shops in Bangladesh is 1,07,592 and nearly an equal number of unlicensed shops are involved in selling OTC and prescription drugs throughout the country. Though presently according to DGDA guidelines, these shops need to have at least one $\mathrm{C}$-grade pharmacist having a training of 12weeks, they don't have any dispensing training and diagnosing or treating ability. Among the professional dispensers $91 \%$ are C-grade pharmacists, $7 \%$ are B-grade (diploma) pharmacists, and $2 \%$ are A-grade (graduate) pharmacists. Nonpharmacists usually learn the trade from different sources especially from the representatives of pharmaceutical companies.

Counterfeit or fake medicines have been a great concern all over the world as well as in Bangladesh. The most grievous impact of counterfeit medicines in Bangladesh was the death of 300 children in 19901992. ${ }^{4}$ Additionally, the death of 25 children was also reported in $2009 .{ }^{4}$ Dispensing is one of the vital elements of the rational use of medicines. It involves preparing and providing medicines to the named person. Dispensing error occurs due to incorrect assembling of the medicines and being dispensed to a wrong person among the waiting customers.

Patient counseling is considered as an important component of pharmaceutical care. As the country has a large population of illiterate and semi-literate people, counseling is compulsory for the patient.

Self-medication is the selection and use of medicines by individuals to treat self-diagnosed illness. It includes purchase of prescription-only drugs without prescription and includes antibiotics, analgesics, vitamins, and OTC drugs. Governments in some countries are increasingly encouraging selfcare of minor illness but increased resistance of pathogens and antimicrobial resistance are occurring due to self-medication which leads to lifethreatening adverse effects. In 2016, DGDA established an accreditation program to standardize the retail drug store to promote good public health. The accredited shops were designated as 'model' outlets once they meet the appropriate standards. There are two tier categorization of these shops: level 1 (Model Pharmacy) which is supervised by at least one A-grade pharmacist with the assistance of B- and C-grade pharmacists and level 2 (Model Medicine Shop) which is supervised by at least one C-grade pharmacist. Now the number of level 1 Model Pharmacies and level 2 Model Medicine Shops are 128 and 82 , respectively according to the DGDA website.

The idea of the model pharmacy came from the Tanzania based 'Accredited Drug Dispensing Outlet' (ADDO) model to create a public-private partnership with the goal of improving access to affordable, quality medicines and pharmaceutical services where few or no registered pharmacies exist and to the population living in rural and peri-urban areas. Following the success of that accreditation program in Tanzania, Management Science for Health (MSH), USA has helped some other countries like Uganda, Zambia and Liberia to implement the accreditation policy. In Uganda 520 shops and in Liberia, 200 shops have been accredited. The pharmaceutical market of Bangladesh is growing rapidly. Now a days, the country is self-sufficient and exporting medicines all around the world but its access to common people is not yet well developed. So, DGDA has recently adopted an accredited program of retail pharmacies which are supervised by A-grade pharmacists where the shops are named as 'Model Pharmacies'. In this study, the current scenario of the model pharmacy concept has been determined and suitability of probable modern systems for better healthcare management and patient's compliance have been evaluated. 


\section{MATERIALS AND METHODS}

This is mainly a survey-based study. The information is gathered from a subset of population by asking them a set of predetermined questions on a specific topic and recording their feedback. The field survey was conducted by a question and answer method using a semi-structured questionnaire. In this questionnaire method, a form containing a predetermined set of questions was used to obtain information from the target individuals about the inquiries made. This project utilized a semistructured questionnaire. The data was collected after obtaining consent from the Model Pharmacy (level 1) personnel. They were informed of all the ethical issues and given assurance of confidentiality of their data.

In this method, 90 model pharmacies out of 128 were deliberately selected from 7 districts (Dhaka, Chittagong, Comilla, Mymensingh, Tangail, Noakhali and Brahmanbaria). The study population included the owner, pharmacist (Grade A, B \& C) and other working staffs of the model pharmacies.

\section{RESULTS AND DISCUSSION}

The number of patients suffering due to imprudent patient counseling and drug distribution system is high. Drug degradation which is a result of inappropriate storage condition is a normal scenario here. On the other hand, the amount of fake or spurious drug is increasing in the market which must be eliminated. Patient counseling must be an integral part while getting drugs from the pharmacies. Appropriate storage of medicines is crucial for treatment success, because a lot of drugs are heat or sunlight sensitive that may degrade in the harsh conditions. Establishing model pharmacy can be a strong measure to combat these circumstances. But, many improvements have to be embraced and rules and regulations should be enacted for better patient care. After surveying and analyzing the data, the undermentioned approaches can be taken into consideration to set up an advanced model pharmacy in order to ensure enhanced patient service.
According to the DGDA, a model pharmacy should have the sign board containing the official logo of the model pharmacy as well as the registration number so that people can distinguish it from the retail pharmacies and get medicines from a safe and reliable source and enjoy other benefits. ${ }^{5}$ From Table 1 it is found that about $98 \%$ of the model pharmacies have their signboard containing registration number and logos.

Table 1 also demonstrates that $32 \%$ model pharmacies have adequate seating, and $77 \%$ model pharmacies have potable water for the waiting patients. Model pharmacy should have enough space as well as potable water where patients can sit and have water in case of long queue of patients. A hygienic washroom must be available in the model pharmacies for the convenience of patients and pharmacy staffs, where the result shows only 51\% model pharmacies have a washroom. Leaflets, posters, brochure, and flyers containing pharmaceutical awareness can be kept for educating the patients.

Counseling should be done in a private space as it is very much personal to any patients. From the survey, it was found that most of the model pharmacies (83\%) do not have a separate patient counseling room. There may be a lot of patients, who may hesitate to discuss in an open place or may not discuss with a pharmacist at all. Again, a pharmacist may not feel comfortable to counsel a patient in an open space. This point should be considered carefully.

There should not be any doctor station inside a pharmacy as it may influence the prescription pattern of the doctors which may result in polypharmacy. Although result shows that only $2 \%$ of model pharmacies have doctors practicing inside.

In case of maintenance of temperature, (below $30^{\circ} \mathrm{C}$ ), it was found that about $88 \%$ model pharmacies maintain it properly (Table 1). This scenario was different in the remaining $12 \%$ of model pharmacies. As the survey was conducted in the winter season, so this can be a reason for this although adequate 
temperature controlling equipment were found to be present.

A model pharmacy has to be operated by adequate number of A-grade pharmacists. In some model pharmacies, only B-grade pharmacists were found working without the supervision of an A-grade pharmacists. In this case, DGDA can make a policy for the B-grade pharmacists for working in the model pharmacies. Inadequacy in workforce diminishes proper functioning of the pharmacy. So, there should be guideline about the actual number of pharmacists working ( $\mathrm{A}, \mathrm{B}$ and $\mathrm{C}$ grade) and their roles and responsibilities like other developed countries. ${ }^{6}$ From this study, it was found that, about $51 \%$ participants told that model pharmacies remain open generally for 13-16 hours and usual opening and closing time is between 8 am to $10 \mathrm{pm}$. Almost every participants admitted that the model pharmacy keep operation for 7 days a week.

Table 2 also shows that A-grade pharmacists were present in only $26 \%$ of the pharmacies. The result is very unsatisfactory and might have occurred due to some facts such as some model pharmacies were surveyed in the public holidays and outside the working hours of the A-grade pharmacists. According to the guidelines proposed by DGDA, the

Table 1. Overview of the physical conditions of a model pharmacy.

\begin{tabular}{|c|c|c|c|}
\hline Sl. & Question & Yes & No \\
\hline 1 & Does this model pharmacy have adequate seating for customer waiting for service? & $32 \%$ & $68 \%$ \\
\hline 2 & Does this model pharmacy have a source of potable water? & $77 \%$ & $23 \%$ \\
\hline 3 & $\begin{array}{l}\text { Does this model pharmacy have a signboard containing the name of the outlet and logo } \\
\text { according to the DGDA guidelines? }\end{array}$ & $98 \%$ & $2 \%$ \\
\hline 4 & $\begin{array}{l}\text { Does this model pharmacy have a signboard containing the registration number according to } \\
\text { the DGDA guidelines? }\end{array}$ & $60 \%$ & $40 \%$ \\
\hline 5 & Is the temperature maintained under $30^{\circ} \mathrm{C}$ ? & $88 \%$ & $12 \%$ \\
\hline 6 & Does this model pharmacy have toilet/washroom? & $5 \%$ & $49 \%$ \\
\hline 7 & Does this model pharmacy have a separate space for patient counseling? & $17 \%$ & $83 \%$ \\
\hline 8 & Is there any doctor practices inside the pharmacy? & $2 \%$ & $98 \%$ \\
\hline
\end{tabular}

Table 2. Overview of the services provided in a model pharmacy.

\begin{tabular}{|c|c|c|c|c|c|}
\hline \multirow{2}{*}{$\begin{array}{l}\text { Sl. } \\
9\end{array}$} & \multirow{2}{*}{$\begin{array}{l}\text { Question } \\
\text { Working hour in a model pharmacy }\end{array}$} & \multicolumn{4}{|c|}{ Answer } \\
\hline & & $8-12$ hour & 13-16 hour & $16-20$ hour & 24 hour \\
\hline & & $5 \%$ & $51 \%$ & $31 \%$ & $13 \%$ \\
\hline \multirow[t]{2}{*}{10} & Duration of operating hours of a model pharmacy & 24 hour & $8 \mathrm{am}$ to $10 \mathrm{pm}$ & 8 am to $12 \mathrm{am}$ & 8 am to $1 \mathrm{am}$ \\
\hline & & $13 \%$ & $51 \%$ & $21 \%$ & $15 \%$ \\
\hline \multirow[t]{2}{*}{11} & \multirow{2}{*}{$\begin{array}{l}\text { How many days the model pharmacy is operational in a } \\
\text { week? }\end{array}$} & \multicolumn{2}{|r|}{5 Day } & 6 Day & 7 Day \\
\hline & & \multicolumn{2}{|r|}{$0 \%$} & $2 \%$ & $98 \%$ \\
\hline \multirow[t]{2}{*}{12} & \multirow[t]{2}{*}{ Was A-grade pharmacist present during the survey? } & \multicolumn{2}{|r|}{ Presence } & \multicolumn{2}{|r|}{ Absence } \\
\hline & & \multicolumn{2}{|r|}{$26 \%$} & \multicolumn{2}{|r|}{$74 \%$} \\
\hline \multirow[t]{2}{*}{13} & \multirow{2}{*}{$\begin{array}{l}\text { What is the number of } \mathrm{A} \text {-grade pharmacist in the } \\
\text { model pharmacy? }\end{array}$} & \multicolumn{2}{|r|}{1} & \multicolumn{2}{|r|}{2} \\
\hline & & \multicolumn{2}{|r|}{$99 \%$} & \multicolumn{2}{|r|}{$1 \%$} \\
\hline \multirow[t]{3}{*}{14} & \multirow{3}{*}{$\begin{array}{l}\text { What is the number of } \mathrm{C} \text {-grade technician in the model } \\
\text { pharmacy? }\end{array}$} & 1 & & $7-10$ & $11-20$ \\
\hline & & 31 & & $23 \%$ & $11 \%$ \\
\hline & & \multicolumn{2}{|r|}{ Yes } & \multicolumn{2}{|r|}{ No } \\
\hline 15 & $\begin{array}{l}\text { Does the dispenser of model pharmacy check or } \\
\text { perform certain patient condition (Blood Pressure, } \\
\text { Blood sugar, Body temp., Body weight, Nebulization, } \\
\text { Malaria test and Pregnancy test) in the pharmacy? }\end{array}$ & \multicolumn{2}{|r|}{$77 \%$} & \multicolumn{2}{|r|}{$23 \%$} \\
\hline 16 & $\begin{array}{l}\text { Does the dispenser of model pharmacy conduct any } \\
\text { medical/clinical services (e.g. giving injection) other } \\
\text { than listed above? }\end{array}$ & \multicolumn{2}{|r|}{$59 \%$} & \multicolumn{2}{|r|}{$41 \%$} \\
\hline
\end{tabular}


A-grade pharmacist must be present in the model pharmacy while it is operational. In this case, more than one pharmacist can be employed, so that at least one of the pharmacists must be available in the pharmacy by roster schedule. Authority should pay attention in this issue and proper legal action should be applied. Although about 4-6 C-grade technicians were found to be present during visit claimed by $35 \%$ respondents.

From the survey, it was found that most of the model pharmacies $(77 \%)$ provide services like diabetes test, blood pressure measurement, pregnancy test etc. Again, about $59 \%$ participants claim that model pharmacies are delivering clinical service like pushing injection. By getting these services, the patients' perception for model pharmacy will be better and this will lead to the concentration of patients in those pharmacies. As a result, people will not be buying drugs which are adulterated, substandard, and spurious anymore. But, the pharmacies should not consider the aforementioned services as a source of income, otherwise this can lead to a disastrous outcome for the patients.

Proper knowledge and training are the main back bone of dispensing of drugs as well as the management of drugs. ${ }^{7}$ Counseling is also dependent on that. From the survey it was found that, almost $100 \%$ pharmacists who are operating the model pharmacy get the training from Pharmacy Council of Bangladesh (PCB), but it should be conducted at definite time intervals with updated knowledge for better patient management and safety.

Storage condition and storage facilities play a pivotal role in a pharmacy because the quality of drugs depends on their storage conditions and facilities. ${ }^{8}$ According to the survey, almost $100 \%$ of the model pharmacies maintain desired temperature for storage of drugs and medicines specially vaccines and insulins. It is also mentioned in the guidelines of establishment procedure of model pharmacies. Besides maintaining temperature and humidity, pharmacists should consider a look-alike and soundalike product (LASA) management. LASA are those products which have similar names or similar looking or both. LASA may create confusion (wrong dose or wrong medication) and wrong medicines may be dispensed. Proper steps should be taken so that LASA products may be kept in different areas with proper procedure like tall man lettering. While procurement of drugs, it should be checked. Greater care should be given during packaging and patients should be well counselled so that they do not take wrong medicine. ${ }^{7}$

From table 3 it was found that in about $81 \%$ of model pharmacies, there is a separate shelf for prescription and OTC medicine. Prescription drugs are stored with tight security in $70 \%$ of the pharmacies. It was found that only $12 \%$ of these pharmacies sell narcotic products but the products with abused potential are kept under high security in $100 \%$ cases. Physicians' sample were found to be sold to customers in only $8 \%$ of model pharmacies. It is not possible to treat a patient with the available marketed dosage form especially for pediatric and geriatric patients. For example, pediatric patients need relatively a lower dose and solution-based medication whereas the geriatric patients need dose adjustment according to their body weight as well as body condition like disease (kidney disease, liver disease etc. .). ${ }^{9}$ It is also helpful in case of emergency. In case of vomiting the medicines can be formulated as suppository or patch system. Extemporaneous section can be incorporated in model pharmacies by ensuring proper facilities and guidelines. Now-adays, doctors are prescribing individualized treatment rather than the traditional one. So, introduction of extemporaneous section in model pharmacies will open a new era for patient compliance. From this study, it was found that no pharmacies have this facility to make extemporaneous medications. They purchase drug organized in unit dosing system and dispense it to the patient in the similar manner. Most of these pharmacies sell non-pharmaceutical products and medical devices which are kept separately from the therapeutic ones. Model pharmacies are authorized to sell traditional medicines like Unani, 
Ayurvedic and Herbal medicines along with allopathic medicines. But, it is strongly recommended to store them separately from the allopathic medicines. From this survey, it was found that about $83 \%$ of the pharmacies sell these alternative medicines and only $35 \%$ of them have separate dispensing unit from the allopathic ones. There is also a need of special consideration for photosensitive products. Almost all the pharmacies return the damaged or expired medicines to the companies according to DGDA guidelines.

Table 3. Condition of the maintenance of storage in the model pharmacy.

\begin{tabular}{|c|c|c|c|}
\hline S1. & Question & Yes & No \\
\hline 17 & Are the 'Prescription medicines' kept separated from the 'OTC medicines' in the model pharmacy? & $81 \%$ & $19 \%$ \\
\hline 18 & Are the 'Prescription drugs' stored well secured in the model pharmacy? & $70 \%$ & $30 \%$ \\
\hline 19 & Does the model pharmacy sales narcotic (the dugs which has potential to be abused) drugs? & $12 \%$ & $88 \%$ \\
\hline 20 & $\begin{array}{l}\text { If sold, then are those narcotics stored with higher security (lock and key or security camera)? } \\
\text { (If not sold, then not applicable) }\end{array}$ & $100 \%$ & $0 \%$ \\
\hline 21 & Does the model pharmacy has a refrigerator? & $100 \%$ & $0 \%$ \\
\hline 22 & Are vaccines and insulins stored between $2^{\circ} \mathrm{C}$ to $8^{\circ} \mathrm{C}$ ? & $100 \%$ & $0 \%$ \\
\hline 23 & Does the model pharmacy sales any physicians's sample which is offered to doctors? & $8 \%$ & $92 \%$ \\
\hline 24 & Does the model pharmcy make any extemporaneous medicine? & $0 \%$ & $100 \%$ \\
\hline 25 & Does the pharmacy purchase any bulk drug that has to be dispensed in a different container? & $0 \%$ & $100 \%$ \\
\hline 26 & $\begin{array}{l}\text { Does the model pharmacy sale any 'Non- pharmaceutical products' and 'Medical Supplies and } \\
\text { Devices'? }\end{array}$ & $96 \%$ & $4 \%$ \\
\hline 27 & If sold, then are those items stored separately from the therapeutic products? & $93 \%$ & $7 \%$ \\
\hline 28 & $\begin{array}{l}\text { Does the model pharmacy sale any DGDA-approved traditional or alternative } \\
\text { (Ayurvedic/Unani/Herbal) medicines? }\end{array}$ & $83 \%$ & $17 \%$ \\
\hline 29 & If sold, then are those items stored separately from the Allopathic medicines? & $35 \%$ & $65 \%$ \\
\hline 30 & $\begin{array}{l}\text { Does the model pharmacy return the 'damaged or expired medicines' to the companies according to } \\
\text { the DGDA guidelines? }\end{array}$ & $100 \%$ & $0 \%$ \\
\hline
\end{tabular}

Table 4. Condition regarding adverse drug reactions (ADR) .

\begin{tabular}{llcc}
\hline S1. & Question & Yes & No \\
\hline 31 & Does the model pharmacy keep adverse drug reaction reporting form? & $0 \%$ & $100 \%$ \\
32 & Does the model pharmacy report all the adverse drug reaction occured? & $0 \%$ & $100 \%$ \\
33 & How many adverse drug reaction episodes have been reported after & Zero & 1 or more \\
& conversion to model pharmacy? & $100 \%$ & $0 \%$ \\
\hline
\end{tabular}

Medicines in a model pharmacy should be purchased from valid sources. From the present data, it was found that the main source of medicines in a model pharmacy is the pharmaceutical companies. It should be put under monitoring whether the manufacturing companies are licensed under DGDA or not. Acquisition of medicines should be done from the pharmaceutical companies which are prominent for following Good Manufacturing Practice (GMP) as prescribed by WHO. Reorder quantity level of drugs should be determined before the remaining inventory is depleted. Lifesaving and fast-moving drugs should be available in the model pharmacy all the time. Medicines should be ordered according to the season also. For example, the demand of antihistamines is increased in the winter. It is a good practice to check the inventory regularly and it should be computerized for convenience. Advantages can be taken from software like system analyses and data processing (SAP). Perpetual inventory system is more accurate than the physical one. Physical inventory may be lost, or error may happen there.

From table 4, it was found that, not a single model pharmacy is containing the adverse drug 
reactions (ADRs) reporting forms. They have not reported any adverse drug reaction yet. So, there is almost no data about the number of adverse drug reaction episodes. It is a must needed tool for detecting the substandard and spurious drugs. If any ADR is informed that should be immediately communicated to the concerned department for evaluation. This would strengthen the health sector and patient's safety will be ensured as well. The concerned authority like Adverse Drug Reaction Monitoring (ADRM) cell can play a vital role in creating the public awareness about adverse drug reactions and to compel all the pharmacies to maintain the adverse drug reaction reporting form.

Online drug delivery system has been proven to be a truly effective method in terms of acquiring medicines from pharmacy in the developed part of the world. Introduction of this system in the model pharmacies can save time of the patient. ${ }^{10}$ Sometimes, finding a pharmacy in countryside area is a tiresome work. Again, it is difficult to say that a medicine which the patient is particularly looking for will be available there. Introduction of Medicine Procurement Database System (MPDS) can be an effective tool to eliminate this type of problem. Through MPDS, finding specific location and medicines will be lot easier. MPDS will surely fortify the online drug delivery system. ${ }^{11}$

Figure 1 shows the salary range paid to an Agrade pharmacist working in the model pharmacies. It was found that $35 \%$ get in a range between 13,000 to $15,000 \mathrm{BDT}$, where $39 \%$ of the A-grade pharmacists get their salary in a range between 16,000 to $18,000 \mathrm{BDT}$ and $22 \%$ get in the range between 19,000 to 20,000 BDT. Government should focus on this issue more closely because pharmacists working in the other sectors like pharmaceutical companies, private and public universities etc. generally get a much higher remuneration than what is paid in these model pharmacies. The pharmacists working here must be paid a satisfactory salary to sustain this system. Other than the salary, they must be paid a bonus like festival bonus, profit sharing etc. Otherwise, the graduate pharmacists might be discouraged in this profession. A positive side is that A grade pharmacist's registration certificate are being found to be displayed by almost all the pharmacies during inspection. About $57 \%$ of A grade pharmacists work for 8-9 hour in a day. In about $96 \%$ cases, the graduate pharmacists have to work for 6 days a week. From this study depicted in table 5, it was also found that about $61 \%$ of pharmacists get their salaries within 6-10 days of the beginning of the month. Although $92 \%$ of graduate pharmacist get their salaries within the fixed timeline, they usually don't get any compensation for overtime. Almost all the pharmacists received 30 hours training by PCB and passed the examination before joining the model pharmacy. From the study, it was also observed that in around $91 \%$ cases, the owners of the pharmacy and other colleagues cooperate with the graduate pharmacists. There has been also a change in the attitude of customers and $94 \%$ of the customers purchase all the medicines mentioned in the prescription. Another good news is that, almost 99\% of the pharmacies keep the purchase records and among these they preserve records of $39 \%$ of all essential products.

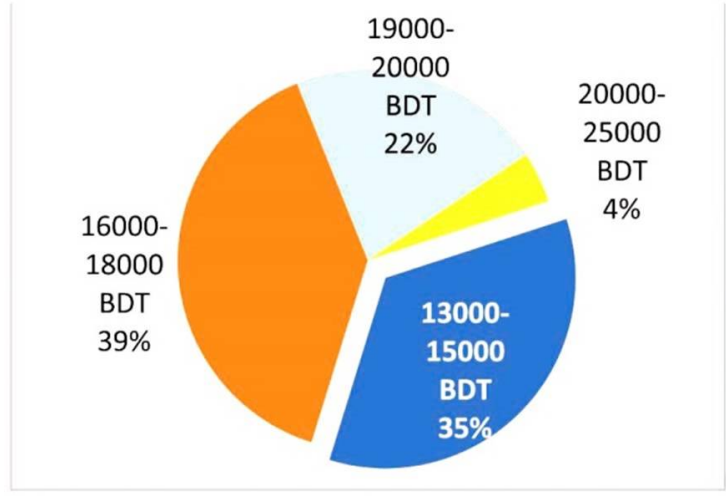

Figure 1. Percentage of salary range of the A-grade pharmacist.

From the survey, a very few percentages of the pharmacies were found to be operational for 24 hours and most of them were for 8 to 20 hours. The model pharmacies can be made more patient friendly by keeping them open round the clock through introducing roaster system for the pharmacists.

From figure 2 we can assess the customers' or patients 'awareness about the model pharmacies. The 
result shows that number of customers has been increased in $52 \%$ of the model pharmacies. While owners or other personnel of $39 \%$ of the model pharmacies think that there are no changes in customer flow. In addition, 9\% personnel of the model pharmacies opine that the customer flow has reduced after conversion to model pharmacies. The main reason for this decrease is the prohibition of selling medicines without prescription. Less customer flow in the model pharmacies might also be due to the lack of awareness among people about the

Table 5. Information about A-grade pharmacist (applicable if present during survey visit) .

\begin{tabular}{|c|c|c|c|c|c|c|c|}
\hline S1. & Question & \multicolumn{6}{|c|}{ Answer } \\
\hline 34 & Is the $\mathrm{A}$-grade pharmacist's registration certificate from & \multicolumn{3}{|c|}{ Available } & \multicolumn{3}{|c|}{ Not available } \\
\hline & $\begin{array}{l}\text { Pharmacy Council of Bangladesh displayed in the model } \\
\text { pharmacy? }\end{array}$ & \multicolumn{3}{|c|}{$100 \%$} & \multicolumn{3}{|c|}{$0 \%$} \\
\hline \multirow[t]{2}{*}{35} & \multirow{2}{*}{$\begin{array}{l}\text { How many hours the A-grade pharmacist has to work in a } \\
\text { day? }\end{array}$} & $6-7 \mathrm{~h}$ & $8-9$ hour & \multicolumn{2}{|c|}{ 10-11 hour } & $12-13$ hour & 14-16 hour \\
\hline & & $4 \%$ & $57 \%$ & \multicolumn{2}{|c|}{$35 \%$} & $4 \%$ & $0 \%$ \\
\hline \multirow[t]{2}{*}{36} & \multirow{2}{*}{$\begin{array}{l}\text { How many days the A-grade pharmacist has to work in a } \\
\text { week? }\end{array}$} & \multicolumn{2}{|c|}{5 Day } & \multicolumn{2}{|c|}{6 Day } & \multicolumn{2}{|r|}{7 Day } \\
\hline & & \multicolumn{2}{|c|}{$0 \%$} & \multicolumn{2}{|c|}{$96 \%$} & \multicolumn{2}{|r|}{$4 \%$} \\
\hline \multirow[t]{3}{*}{37} & \multirow[t]{2}{*}{ When does the A-grade pharmacist get his/her salary? } & \multicolumn{2}{|c|}{ Date $1-5$} & \multicolumn{2}{|c|}{ Date $6-10$} & \multicolumn{2}{|c|}{ Date $11-15$} \\
\hline & & \multicolumn{2}{|c|}{$26 \%$} & \multicolumn{2}{|c|}{$61 \%$} & \multicolumn{2}{|c|}{$13 \%$} \\
\hline & & & & & & Yes & No \\
\hline 38 & \multicolumn{5}{|c|}{ Does the A-grade pharmacist get his salary within the fixed timeline? } & $92 \%$ & $8 \%$ \\
\hline 39 & \multicolumn{5}{|c|}{ Does the A-grade pharmacist get compensation if $\mathrm{s} /$ he has to work more than the fixed work hour? } & $0 \%$ & $100 \%$ \\
\hline 40 & \multicolumn{5}{|c|}{ Did the A-grade pharmacist receive 30 hours training from the Pharmacy Council of Bangladesh? } & $100 \%$ & $0 \%$ \\
\hline 41 & \multicolumn{5}{|l|}{ Did the A-grade pharmacist pass the exam after training? } & $100 \%$ & $0 \%$ \\
\hline 42 & \multicolumn{5}{|c|}{$\begin{array}{l}\text { After model pharmacy has a compulsory obligation to employ you here do the owner and the other } \\
\text { colleagues cooperate with you? }\end{array}$} & $91 \%$ & $9 \%$ \\
\hline 43 & \multicolumn{5}{|c|}{ Do all the customers buy all the medicines mentioned in a prescription from this pharmacy? } & $94 \%$ & $6 \%$ \\
\hline 44 & \multicolumn{5}{|l|}{ Does the model pharmacy keep the purchase records? } & $99 \%$ & $1 \%$ \\
\hline \multirow[t]{2}{*}{45} & \multirow{2}{*}{$\begin{array}{l}\text { Does the model pharmacy keep all the record of medicines } \\
\text { sold to the customers? }\end{array}$} & All & Antibio & & Other & & ecord \\
\hline & & $39 \%$ & $22 \%$ & & $0 \%$ & & $\%$ \\
\hline
\end{tabular}

Table 6. Information about C-grade technicians.

\begin{tabular}{|c|c|c|c|c|}
\hline Sl. & Question & & Answer & \\
\hline \multirow[t]{2}{*}{47} & \multirow{2}{*}{$\begin{array}{l}\text { Has the number of customers increased or decreased after converting this } \\
\text { pharmacy into a Model Pharmacy? }\end{array}$} & Increased & Decreased & No change \\
\hline & & $52 \%$ & $9 \%$ & $39 \%$ \\
\hline \multirow[t]{2}{*}{48} & \multirow{2}{*}{$\begin{array}{l}\text { After conversion to Model Pharmacy, an A-grade pharmacist is working here. } \\
\text { Does it help or trouble the operation? }\end{array}$} & Benefit & Trouble & No change \\
\hline & & $97 \%$ & $1 \%$ & $2 \%$ \\
\hline \multirow[t]{2}{*}{49} & What is the source of purchasing medicines in the model pharmacy? & $\begin{array}{c}\text { Pharma } \\
\text { Companies }\end{array}$ & Other Sources & No Idea \\
\hline & & $100 \%$ & $0 \%$ & $0 \%$ \\
\hline
\end{tabular}

newly established model pharmacies. Maximum people $(97 \%)$ also think that employment of A-grade pharmacist in these model pharmacies can help to tackle difficult situation. Another very satisfactory result is found in table 6 , which shows that $100 \%$ of the model pharmacies purchase medicines from the pharmaceutical companies. One of the main targets of establishing model pharmacy was to eradicate fake drugs from the local market. By ensuring purchase from pharmaceutical companies directly, it can be assured that patients will get quality drugs. 


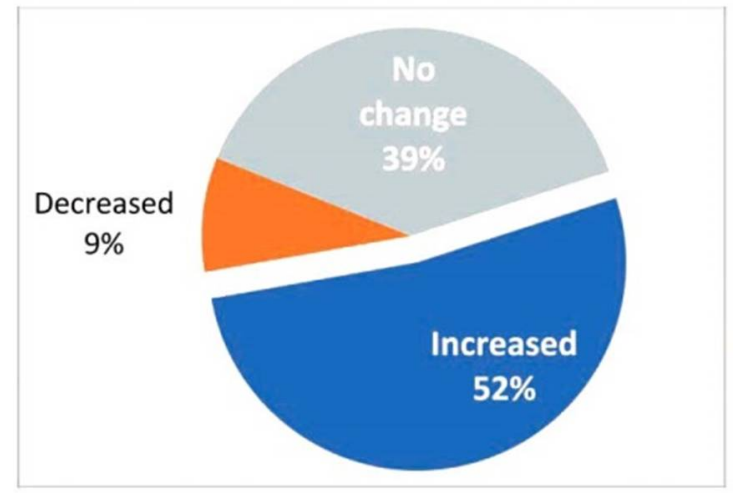

Figure 2. Overall percentage of model pharmacies where the number of customers has been increased or not after conversion.

Obviously, there is an increased expense in operating these pharmacies, so the DGDA should take prompt actions to create public awareness otherwise this concept may deem ineffective before emerging as there is an issue of higher overhead expenses than the regular ones. Some stakeholders are in opinion that the DGDA may take some initiatives like -

- Making a budget for the promotional exposures. During the establishment of ADDO in Tanzania, they had a budget solely for promotional purpose. $^{13}$ Awareness and promotion can be done by advertising in the television, radio, newspaper, billboards etc.

- Making it illegal for any other retail medicine outlet to sell prescription medicines; therefore, selling prescription medicines will give model pharmacies a significant advantage over other retail pharmacies.

- Providing some soft loans to the owners.

The model pharmacy pilot program has been completed but no evaluation report is published yet to go for the roll out program. The evaluation report of the pilot project is required for reconstructing the program strategies and implement in rolling out this program throughout the country.

These are the things which were evolved as suggestions from various stakeholders that can be taken under considerations by the concerned authority for introducing a more effective model pharmacy which will be more equipped with modern facilities and safe.

\section{CONCLUSIONS}

The study shows that many of the recently introduced model pharmacies are maintaining some facilities like enough seat, potable water, toilet etc. for the waiting customers which are found barely in old retail pharmacies. These facilities should be maintained in $100 \%$ of all the model pharmacies. Among the 128 inaugurated model pharmacies, almost 50\% are in the Dhaka city and a separate place for patient counseling is found only in those model pharmacies located in this city. But this facility is almost nil in other cities. Almost all the model pharmacies were found to have one A-grade pharmacist employed. In one model pharmacy in Dhaka, two A-grade pharmacists were employed which is a very good and appreciable approach indeed, but unfortunately, they do not work in a roster schedule and none of them could be found during the survey visit. The A-grade pharmacist should be the de facto supervisor of overall operations in the model pharmacy, but this phenomenon was absent. The study observed that most of the model pharmacies are offering and performing some minor tests of certain body conditions and this is good for acquiring public trust. The overall storage condition of medicines in the model pharmacies was satisfactory. In terms of keeping records of purchased drugs, it was found that almost all the model pharmacies keep the invoices for a certain period but the record keeping of the medicines sold is unsatisfactory. Other than this, some model pharmacies keep records of the antibiotics sold by manually writing in a book. The most satisfactory result of this survey was pharmacies are purchasing medicines directly from DGDAapproved pharmaceutical companies. By doing so, they are ensuring quality drugs to the customers. The results also suggest that due to lack of awareness, most of the population in the vicinity of the model pharmacies do not go there. As it is a public-private partnership program, the government and stakeholders must come forward to create awareness among the public. 
This survey work only encompasses studying some of the features of the model pharmacies in Bangladesh. Further studies are required on the benefits and other consequences of model pharmacies like rationale use of the drugs and patient knowledge on the safe use of drugs that they are consuming.

\section{ACKNOWLEDGEMENT}

The authors are grateful to the authority of Faculty of Pharmacy, University of Dhaka for the cordial help and support during the study.

\section{REFERENCES}

1. Directorate General of Drug Administration (DGDA), Government of Bangladesh, 2018.

2. Chowdhury, P.M. 2010. An overview of the pharmaceutical sector in Bangladesh. BRAC EPL RESEARCH, p. 1-24.

3. Ahmed, S.M., Hossain, M. A. and Chowdhury M. R. 2009. "Informal sector providers in Bangladesh: how equipped are they to provide rational health care?" Health Policy and Planning 24. 467-78.

4. Andrew, B. J., \& Tomson, G. (1995). Making National Drug Policies a Development Priority. dialogue, 1.
5. http://www.dgda.gov.bd/index.php/2013-03-31-05-1629/guidance- documents/175- guideline- for- modelpharmacy (accessed on 21.12.17).

6. Alomi, Y.A. 2016. A new guidelines on hospital pharmacy manpower in Saudi Arabia. J. Pharm. Pract. Commun. Med. 2, 30-31.

7. Saha, T., Bhuiyan, R.H., Masum, Z.U., Islam, M.R. and Chowdhury, J.A. 2017. Hospital pharmacy management system and future development approaches in Bangladeshi hospitals. Bangladesh Pharm. J. 20, 181-188.

8. British Pharmacopoeia. London: Medicines and Healthcare products Regulatory Agency; 2009. 1141-1149.

9. Woods, D.J. 1997. Extemporaneous formulations - problems and solutions. Ped. Perinatal Drug Ther. 1, 25- 29.

10. Elias- Al-Mamun, M., Saha, T. and Islam, M.R. 2016. Initiation and maintenance of diseases and diagnostic databases of Bangladeshi individuals. Am. J. Pharm. Health Res. 4, 30- 42.

11. Saha, T. 2017. Medicines procurement system from database system (MPDS) for Bangladeshi individuals: a proposal. Der Pharmacia Sinica. 8, 9- 12.

12. Islam MS. 2006. A review on the policy and practices of therapeutic drug uses in Bangladesh. Calicut Med. J. 4, e2.

13. Accredited Drug Dispensing Outlets in Tanzania: Strategies for Enhancing Access to Medicines Program Final Report, Management Sciences for Health, Massachusetts, 2017. 